\title{
ENTRE LA ESPERANZA Y EL RECELO: ACERCA DE LA TEORÍA DEL ARTE EN THE MARBLE FAUN DE NATHANIEL HAWTHORNE
}

\author{
$M^{a}$. Ángeles Toda Iglesia
}

La última novela publicada de Hawthorne, The Marble Faun (1859), narra las experiencias de tres artistas estadounidenses en Roma, por lo que no resulta sorprendente que esté cuajada de descripciones, críticas y reflexiones referentes a distintas obras de arte. Todas ellas sirven al autor para evocar el ambiente de la Roma de mediados del siglo diecinueve, para caracterizar a los personajes, y para subrayar el tema de la experiencia y la culpa, pero cumplen también una función más central. The Marble Faun es sobre todo un estudio de la naturaleza y propósito del arte y de su relación con la vida, desde el punto de vista tanto del proceso creativo como de la recepción. A través de comentarios y reflexiones de los personajes o del narrador, Hawthorne va formulando una teoría del arte con connotaciones fuertemente Románticas, pero matizada por sus propios recelos hacia la creación artística.

A grandes rasgos, se pueden establecer desde el principio las tres premisas fundamentales del arte desde el punto de vista de Hawthorne en esta obra. En primer lugar, el arte debe transmitir vida en su representación de la realidad; por añadidura, lo emocional debe predominar sobre lo intelectual, tanto en la creación como en la contemplación del arte; y, por último, el arte debe cumplir una función transcendental, sirviendo no sólo como expresión de quien crea, sino como acercamiento a las verdades eternas, de un modo que se aproxima a la imagen platónica del universo. Todas estas premisas son, obviamente, parte de la teoría Romántica del arte; sin embargo, cada una de ellas recibe una serie de matizaciones y especificaciones cruciales por parte del autor. En ellas se reflejan tanto sus miedos y obsesiones personales como una serie de preocupaciones de su época, tales como el papel de las mujeres como creadoras de arte; como comenta Lewis, The Marble Faun es también "a novel about the heroine as artist" (1966:75). A través de sus reflexiones sobre distintas obras plásticas, ya sean reales (como el Fauno de Praxíteles, el retrato de Beatrice Cenci y el San Miguel arcángel de Guido Reni, que reciben comentarios detallados) o piezas imaginarias realizadas por las dos pintoras y el escultor que protagonizan la trama, Hawthorne profundizará en estos presupuestos Románticos del arte, revelando en muchos casos el precario equilibrio entre contrarios sobre el que se sustentan.

La primera premisa, la obligación del arte de representar la realidad de un modo a la vez fiel y vivo, plantea varias cuestiones: las relaciones del arte con la realidad, los posibles falseamientos en la representación artística, y los requisitos para plasmar una imagen 
verdadera del mundo. Matthiessen comenta que la falta de "aesthetic sophistication" de Hawthorne hacía que le inquietase el hecho de que la mayoría de las obras artísticas no reprodujeran fielmente la naturaleza en el sentido más básico (1941:353); no obstante, y como es de esperar de un escritor en cuyo arte el simbolismo desempeña un papel crucial, el realismo que persigue Hawthorne va más allá de la simple exactitud objetiva.

Esto se hace evidente en la primera descripción detallada, la del Fauno de Praxíteles, en la que se establece el parecido de la estatua con uno de los protagonistas de la novela, Donatello. Mientras la similitud observada se reduce a los rasgos físicos, la afirmación de Matthiessen tiene cierta base: Hawthorne parece aseverar que uno de los méritos del gran arte clásico es su capacidad de reproducir individuos reales, hasta el punto de que existen en el presente seres humanos que podrían haber sido sus modelos. Sin embargo, y al igual que en los otros casos en los que se establece un parecido entre un personaje "real" y una obra de arte (los gestos de Miriam y de Hilda que las asemejan al cuadro de Beatrice Cenci, el modelo de Miriam que podría haber posado para el demonio de Reni), lo importante no es la semejanza física, sino las implicaciones morales o simbólicas que se revelan a través de esa semejanza: la culpabilidad o el sufrimiento de las dos pintoras, el carácter maligno del modelo.

Así, la semejanza de Donatello con el Fauno funciona a lo largo de toda la obra como una imagen de la ambigua realidad moral que encarna el joven italiano, y su valor principal es el de proporcionar una cierta aproximación a una idea que se presenta como intemporal. Según el narrador, el artista ha plasmado "a poet's reminiscence of a period when man's affinity with nature was more strict," es decir, algo perteneciente a un pasado remoto y semi-mítico. En cambio, el diálogo que sigue entre los personajes subraya la continuidad del tema a través del tiempo: como miedo presente para Hilda, como añoranza del pasado para Kenyon, o como deseo para el futuro desde el punto de vista de Miriam (32-33).

De este modo, la vitalidad de las obras de arte se relaciona estrechamente con su vigencia en el presente. La cuestión reviste una importancia especial para Hawthorne como autor americano influído por la iconoclasia antitradicionalista del transcendentalismo, pero a la vez obsesionado por la necesidad de examinar el pasado, como señalan Matthiessen (1941:355) y Lewis (1966:79-80). Así pues, de la descripción del Fauno se desprende que el auténtico arte debe ser verosímil en el sentido de reflejar realidades morales más allá de la mera apariencia física. Para conseguirlo, debe evitar caer en los distintos falseamientos que pueden distorsionar la realidad.

Uno de estos falseamientos consiste en intentar conseguir una semblanza de realidad y vida limitándose a la imitación servil de los detalles físicos. A raíz de la visita al taller de Kenyon, se introduce la idea, sobre la que se volverá a menudo: la exactitud en la reproducción de "their buttons and button-holes, their shoe-ties, their neck-cloths" que tanto valora el público en las estatuas son según el narrador tan sólo indicios de una habilidad meramente manual y mecánica (119). El "Mefistófeles" interno que tienta a Hilda hacia el final de la novela desarrolla el mismo tema, al incitarla a creer que el único arte salvable y verosímil es el realismo de los flamencos y holandeses (306). Steiner relaciona este rechazo 
de ciertas formas de verosimilitud con la oposición entre "romance" y novela realista como medios alternativos de representar la realidad (1991:91); en este debate, Hawthorne se situará repetidamente en el lado del "romance," justificándose de modo explícito en los prólogos de varias de sus obras.

No obstante, los motivos de Hawthorne para condenar el exceso de realismo van más allá de la defensa de una forma de representación frente a otra, y apuntan a un miedo a que este exceso manifieste aspectos inaceptables de la realidad. Dicho temor se pone de manifiesto en las críticas soterradas que se dirigen a algunas de las obras de Miriam, con su perspectiva pesimista y sarcástica. El trazo que convierte a su Jael en una asesina vulgar, capaz de registrarle los bolsillos al hombre que acaba de matar, se interpreta como un añadido final, algo que destruye "a high, heroic face of lofty beauty" (59), es decir, algo que estropea una representación más clásica y más ortodoxa de la heroína bíblica. Del mismo modo, la brillante e irónica crítica que Miriam realiza del atildado arcángel de Guido Reni, que lucha con el mal sin despeinarse, es al principio recogida por Kenyon, que le sugiere que pinte su propia versión, mucho más violenta y barroca, del combate; pero en seguida es la propia Miriam la que rehúsa hacerlo, expresando en términos humorísticos el miedo a que el exceso de verosimilitud la obligue a reflejar otra realidad inadmisible: "Just fancy a smokeblackened, fiery-eyed demon, bestriding that nice young angel..." (176).

Más allá de la controversia entre realismo y "romance", el realismo en el arte puede revelar más de lo deseable, tanto del tema tratado como de la personalidad de quien crea. Es casi un lugar común la importancia obsesiva que reviste el tema de la ocultación y la revelación de la personalidad en la vida y en la obra de Hawthorne. Los ejemplos abundan, desde los esbozos de argumentos recogidos en sus diarios hasta la temática de novelas enteras. Baste ver cómo el gentil narrador del prólogo de Mosses from an Old Manse, tras involucrar con una pregunta engañosa al lector curioso, erige con arrogancia sus barreras:

Has the reader gone wandering, hand in hand with me, through the inner passages of my being, and have we groped together into all its chambers, and examined their treasures and their rubbish? Not so. . . So far as I am a man of really individual attributes, I veil my face. (1987: 287)

Por otra parte, Hawthorne también es consciente de que la mímesis artística debe guardarse del peligro opuesto al que entraña el exceso de realismo: el exceso de idealización, que se percibe también como un falseamiento. Es tópico que este tema, tan a menudo formulado como crítica contra el arte producido por mujeres, se trate en relación con Hilda, a quien por su carácter virginal no se le supone experiencia que le permita ser más realista. Sus cuadros originales son "delicately imagined, lacking, perhaps, the reality that comes only from a close acquaintance with life"; contemplan a la humanidad con ojos de ángel, a través de la fantasía y el sentimiento (68). Hawthorne no le ahorra alabanzas por haber optado por la copia de los grandes maestros en lugar de la producción de este tipo de arte, "pretty fancies of snow and moonlight" (73). Resulta irónico, aunque significativo, que la nieve y la luz de luna sean imágenes recurrentes en la escritura del propio Hawthorne, y que la luz de luna sea precisamente el símbolo escogido en "The Custom House" para 
representar el mundo intermedio del "romance," el territorio a medio camino entre lo real y lo imaginario que desea recrear en sus obras, y que es el centro de la imaginación poética en sí. En esta contradicción existe una coherencia oculta si se considera que todo el texto de "The Custom House" constituye una justificación no del todo irónica del autor frente a sus antepasados por el hecho de dedicarse a algo tan poco serio, incluso tan poco viril, como la literatura. Como comenta Borges,

like Stevenson, also the son of Puritans, Hawthorne never ceased to feel that the task of the writer was frivolous,or what is worse, even sinful. (1987:441)

El recelo de Hawthorne hacia el arte (incluído el suyo) se manifiesta en sus comentarios sobre Hilda de un modo un tanto indirecto, pero de hecho la validez del arte es una de las cuestiones centrales del libro, y por momentos parece más que dudosa. Volviendo al tema de la idealización y el realismo, ya se ha explicado que el debate que en la novela se centra en las artes plásticas tiene su contrapartida en un debate literario, en un momento en que coexisten corrientes realistas y románticas. Cuando Hawthorne presenta el estudio de Miriam como

the outward type of a poet's haunted imagination, where there are glimpses, sketches, and half-developed hints of beings and objects grander and more beautiful than we can anywhere find in reality,

Hawthorne no se limita a subrayar el concepto Romántico de la unidad esencial de las artes. Al aprobar el elemento de transformación y artificio que representa la iluminación cuidadosamente velada del taller, está especificando algunos de los requisitos necesarios para obtener la verosimilitud y la vida en cualquier arte. La referencia a la estilización que lleva a cabo Kenyon en su Cleopatra insiste sobre el mismo tema. Según el narrador, los ropajes y el tocado de la estatua han sido estudiados minuciosa y escrupulosamente para ser fieles a la realidad del antiguo Egipto, pero hay un elemento de transformación: el tocado, por ejemplo, ha sido "softened into a rich feminine adornment without losing a particle of its truth" (127).

La estilización admisible que se ejemplifica con la Cleopatra enlaza con otro de los requisitos implícitos de la auténtica verosimilitud: el equilibrio entre el individuo y el tipo. Esta preocupación, de orígenes dieciochescos, se repite a lo largo del texto, y aparecía ya en el prólogo citado de Mosses. Además de marcar las distancias, Hawthorne expresa en dicho texto un credo artístico más Clásico que Romántico, al proponer como objeto legítimo del arte lo que atañe a las cualidades comunes y abstraíbles a todo ser humano por encima de la revelación de la individualidad ("Mosses" 287). La verdad que el arte debe imitar va más allá de la realidad concreta de cada individuo. En The Marble Faun, la Cleopatra combina la individualidad de sus rasgos egipcios con su representación de la majestad en su época (12728); del mismo modo, el Fauno es a la vez "strange" y "true and natural" (31). La misma alabanza implícita reciben los cuadros "públicos" de Miriam, que aúnan la observación concreta de escenas domésticas con una visión representativa de la vida femenina (60-61). La estructura arquetípica del "romance," por otra parte, se sustenta justamente en un equilibrio 
entre fórmula y variación paralelo al que Hawthorne propone entre individuo y tipo para el arte plástico (Cawelti 1976:43)

La proporción justa entre realismo y estilización, entre individuo y tipo, es resultado en última instancia del conocimiento profundo de la verdad interna de lo representado, mediante un proceso que es a la vez intelectual y emocional. En esto consiste la prueba definitiva de la verosimilitud. La Cleopatra es fiel a la realidad por el estudio del arte egipcio que inspira sus vestiduras, pero mucho más por la percepción de su carácter, obtenida a base de "thought, emotion, toil of brain and hand" (128). Igualmente, el busto de Milton también esculpido por Kenyon refleja el genio del escritor porque incorpora no sólo un conocimiento de las representaciones anteriores de su figura, sino una lectura profunda de su obra (120). También es éste el mérito de las copias de Hilda, especialmente de la Beatrice Cenci, cuya reproducción sólo se permite bajo las condiciones en que la realiza la artista: no copiando directamente los rasgos, frente al modelo, sino comprendiendo y recordando su esencia para luego plasmarla (76).

Todo lo anterior remite a la segunda premisa que Hawthorne establece para el arte: la creación y la recepción artísticas deben ser procesos en los que predomine lo emocional sobre lo intelectual, aunque sin excluir este último elemento. Como comenta Honor con respecto a la escultura, el arte Romántico tiene como finalidad apelar a los sentimientos, hacer sentir, pero también hacer pensar (1981:132). Desde el punto de vista de la creación, las obras que reciben mayores alabanzas en la novela son las que aúnan la inspiración, en el sentido más pleno de una fuerza creadora ajena a la personalidad consciente del artista, con un dominio de la técnica que haga posible su expresión. La cita ya mencionada con respecto a la Cleopatra de Kenyon --"thought, emotion, toil of brain and hand"-- es la formulación más clara de este ideal, pero la misma cualidad se atribuye a las obras de Hilda, independientemente de que no sean originales. Hilda combina "a deep and sensitive faculty of appreciation," un don de "sympathy" que la hace convertirse en un instrumento de los grandes maestros a los que copia, con "a nicety and force of touch" que dan calidad a su obra (69-72).

Por contraste, las obras en las que falta alguno de los dos aspectos (técnica o inspiración) son condenadas más o menos explícitamente. Las críticas a la falta de técnica que muestran los cuadros de Miriam se ponen en boca de supuestos artistas rivales, pero el narrador no se disocia del todo de ellas, como demuestra una lectura atenta de su comentario:

Whatever technical merit they lacked, its absence was more than supplied by a warmth and passionateness, which she had the faculty of putting into her productions (39; subrayado mío)

La implícita acusación de diletantismo es tan tópica en la crítica sobre artistas femeninas como la del exceso de idealización que se atribuía a Hilda; Chadwick subraya además el cinismo que supone en una época en que a las mujeres se les negaba o dificultaba el acceso a la formación técnica (1992:200). Es importante reconocer este elemento específico en lo que podría parecer una defensa de lo emocional sobre lo técnico, de acuerdo con la teoría Romántica. Sí es cierto, al mismo tiempo, que la condena es mucho más dura hacia las 
obras que carecen de contenido emocional aunque sean técnicamente perfectas. Uno de los signos del cambio producido en Hilda --que en mi opinión, y en contra de cierta tendencia crítica (Porte 1969:139, Lewis 1966:84, Matthiessen 1941:356), sí evoluciona como personaje-- es que llega a detectar y a criticar el elemento falso de buena parte de la pintura italiana, que reside precisamente en colocar

a keen intellectual perception, and a marvellous knack of external agreement, instead of live sympathy and sentiment. (308)

Carentes de otro mérito que el estético, como señala Buonomo, los cuadros de esta clase se convierten en meros artefactos (1996:53).

La palabra "sympathy" es crucial en el texto y aparece prácticamente en todas las descripciones de obras artísticas. Esta capacidad sobre todo pasiva y receptiva, tan vinculada al concepto Romántico de la contemplación, es la esencia misma de la experiencia del arte, que deben compartir la persona que crea y quien contempla la obra. Desde el prefacio de las Lyrical Ballads hasta "The Poet" de Emerson, la teoría Romántica del arte postula que la diferencia entre el artista y el resto de la humanidad es tan sólo de grado, y los lazos entre ambos se establecen a través de la sensibilidad que en potencia comparten. Las obras artísticas, según esta teoría, pueden provocar distintos grados de respuesta, desde la meramente estética y sensual hasta la más deseable: la "sympathy," esa disponibilidad emocional que permite una auténtica comprensión de su mensaje. Ya en el primer capítulo, frente al Fauno, Kenyon reivindica de modo radical el papel activo del espectador en la producción de arte:

It is the spectator's mood that transfigures the Transfiguration. I defy any painter to move or elevate me without my own consent and assistance.

Para Hawthorne es el espectador quien tiene el poder de crear significado y magia, "to change picture into narrative" (Steiner 1991:98). La discusión sobre los posibles modos de interpretar la expresión de la Beatrice en el capítulo así titulado es un desarrollo práctico de esta teoría, que según Steiner anticipa "the broad outlines of reader-response criticism" (92).

Si la sensibilidad receptiva del espectador o espectadora es tan importante para completar el significado de la obra de arte es porque ésta se concibe ante todo como expresión. En primer lugar, la obra es expresión de quien la crea, pero además, como resultado de la inspiración, puede expresar ideas que sobrepasen las intenciones del artista. Como afirma Hilda, las mejores obras de arte son las que ofrecen la posibilidad de que quien las contemple con "sympathy" perciba

a great deal more in them than the poet or artist has actually expressed. Their highest merit is suggestiveness.

No falta, desde luego, en la novela la mitificación del artista tan propia de este período, que interpreta la obra como reflejo de su personalidad, más valiosa como proceso que como producto: "In Shakespeare's tomb lies more than Shakespeare ever wrote," como proclama Melville en "Hawthorne and his Mosses" (1987:343). Al menos en el caso de Kenyon, 
Hawthorne comparte la tendencia de preferir el boceto espontáneo a la obra terminada, algo que Honor considera característico del Romanticismo (1981:17): la escultura de barro es

the intimate product of the sculptor himself, moulded throughout with his loving hands, and nearest to his imagination and heart. (118)

No ocurre así, en cambio, en el caso de Miriam y Hilda, cuyos bocetos personales reciben menos elogios que sus obras acabadas; los límites aceptables de la expresión directa e íntima del yo del artista cambian cuando el artista es una mujer. Del mismo modo que para Gilbert y Gubar la novela proporciona a las escritoras del siglo XIX un medio respetable, por indirecto, de expresar su subjetividad, disfrazándola con la voz narrativa, el cuadro elaborado para su visión pública es un medio respetable porque encubre suficientemente la personalidad de la creadora. Por el contrario, los esbozos inacabados y espontáneos, como la poesía lírica, transgreden la prohibición que impide a las mujeres afirmar su subjetividad como un "yo" central, fuerte y definido (1984:548). Frente a la mirada de Donatello, Miriam, de hecho, repudia sus bocetos personales, atribuyéndolos a un poder fuera de su control consciente (60).

En el caso de Miriam y Hilda, ese poder inconsciente (la inspiración que permite al artista plasmar sus emociones) se percibe como algo especialmente peligroso, no sólo por lo que puede revelar, sino por el efecto que pueda tener sobre ellas. El episodio en que Kenyon, de forma fortuita, captura en la arcilla la expresión exacta de Donatello al cometer el asesinato es uno de los muchos casos de revelación de lo oculto a través del arte que se dan en la novela, pero en ningún caso supone un peligro para el propio escultor (251). En cambio, la extrema sensibilidad de las dos pintoras hace que sus contactos con lo inconsciente a través del arte tengan sobre ellas un efecto directo y casi patológico. El benévolo alemán que se encuentra a una Hilda consternada por las revelaciones de la Beatrice Cenci le aconseja que abandone Roma, puesto que el poder de los grandes maestros es demasiado para "the slender hand, the fragile mind and the delicate heart of a young girl" (301); igualmente, se sugiere que el origen de los males de Miriam puede estar en los efectos estimulantes y agotadores del arte (51). Irónicamente, la mayor imaginación, emoción y sensibilidad que se atribuyen en el siglo XIX tanto a "la mujer" como "al artista" (masculino) ponen en peligro a las mujeres cuando intentan ser artistas. En su caso, y bajo el peso de todo el discurso médico-psicológico del siglo XIX sobre la fragilidad física y mental de la salud femenina, ${ }^{1}$ el segundo requisito de la creación artística (el predominio de lo emocional sobre lo intelectual) aparece considerablemente matizado, sobre todo en lo que se refiere al arte como expresión.

Las exigencias del arte según The Marble Faun son particularmente complejas en el caso de las mujeres, pero en último término Hawthorne nunca pierde de vista la idea de que la expresión de la personalidad del creador (o creadora) está en todo caso supeditada a la verdadera función del arte. Cuando se cumplen toda la complicada serie de requisitos que se 
han venido enumerando, cuando se consigue el equilibrio precario entre realismo e idealización, tipo e individuo, inspiración y técnica, emoción e intelecto, expresión de quien crea y "sympathy" de quien mira, el arte puede llevar a cabo su función verdadera alumbrando una realidad preexistente y eterna, hasta alcanzar una transcendencia casi religiosa. Quizá el ejemplo más explícito de esta teoría semi-platónica del arte sea la referencia a la antigua metáfora de la forma aprisionada en el bloque de mármol, a la que sólo queda sacar a la luz (119). Los verdaderos artistas descubren y revelan las formas e ideas que ya existen, dándoles una expresión plástica que quizá precisamente por su mayor capacidad de sugerencia es capaz de eludir lo intelectual y limitado del lenguaje verbal para comunicar la realidad inefable. Así, el Cristo atado a la columna de Sodoma expresa la doble naturaleza de Jesús mejor que todos los teólogos (309).

No es casualidad que la cita se refiera a un cuadro de tema sacro; la conexión del arte con la religión, o más exactamente con un sentimiento casi religioso, es a la vez característica del Romanticismo y una preocupación particular de Hawthorne. Lewis sugiere que para Hawthorne, "creativity was an analogous, possibly even an alternative, route to salvation" (1966:79). Si bien en momentos de exaltación Hawthorne parece confiar en esta ruta, ya hemos analizado en suficiente detalle sus dificultades y sus riesgos como para comprender que a la vez el escritor es consciente de una gran cantidad de posibles interferencias que pueden interponerse entre el arte y su función, empezando por el propio artista. Por tanto, la escena en la que el autor arremete contra la iglesia católica por su costumbre de mantener los cuadros cubiertos con una cortina que sólo se descorre previo pago tiene a la vez un alcance literal y simbólico (175). En el nivel literal, la costumbre obstaculiza la verdadera función de los cuadros, que Hawthorne reconoce: guiar a los fieles hacia la salvación. En el metafórico, la cortina representa todo lo que se interpone entre el arte y la posibilidad de éste de llevar a cabo su propósito transcendental, su capacidad de transformar la vida aunque no sea más que ofreciendo a quien mira imágenes a través de las cuales puede reconocerse. Como señala también Lewis, la salvación a través del reconocimiento en el arte es uno de los temas centrales del libro (1966:77).

El arte de los grandes maestros sin duda cumple esta función al menos para algunos de los personajes, enseñándoles facetas de su propia naturaleza que les es preciso reconocer para avanzar. Sin embargo, en cuanto a las posibilidades del arte creado por ellos mismos, la conclusión de la obra es más bien desesperanzadora. Si bien a tres de los personajes principales (o a los cuatro, si se considera que el aprendizaje moral de Donatello se completa en la cárcel) se les ofrece un futuro vital y una posibilidad de regeneración, no se hace mención alguna de su futuro artístico, ni del posible reflejo de su experiencia en su producción posterior. La única excepción es Hilda, cuya contacto indirecto con el mal y el sufrimiento le han dado una percepción más amplia y profunda, pero también más crítica, del arte. Irónicamente, esta nueva actitud dificulta sus tareas como copista, interfiriendo con la "sympathy" que antes le permitía rendirse devotamente y captar la esencia de cualquier obra de arte. Pero aquí Hilda recibe --y no por primera vez-- la aprobación completa del 
narrador, que hace suyo el aprendizaje de la artista confirmando la imposibilidad de que el arte sea fiel a su elevada misión de comunicar lo sagrado:

How, indeed, could she have found such? How could holiness be revealed to the artist of an age when the greatest of them put genius and imagination in the place of spiritual insight, and when, from the Pope downward, all Christendom was corrupt? (339)

Cabe pensar que la cita se refiere al período renacentista, en el que se produjeron la mayor parte de las obras que Hilda copia o contempla; pero hay razones para extender su alcance. The Marble Faun es la última obra completada de Hawthorne, escrita cinco años antes de su muerte y durante un período que Besanzon describe como un complejo "final crack-up" (1973:xvi). La corriente de pesimismo y la actitud escéptica de Hawthorne hacia las posibilidades y la utilidad de cualquier arte, ya presentes en obras anteriores, encuentran aquí su máxima expresión. El arte puede quizá dar propósito y significado a la vida humana, ofrecer reflejos y paralelismos, pero en cambio la combinación de cualidades necesarias para producir un arte capaz de expresar la misma esencia intemporal de la realidad, un arte vital que comunique a través del sentimiento sin engañar a la inteligencia, es tan rara que parece inexistente, y no queda más remedio que conformarse con los vanos esfuerzos de la imaginación y el genio por alcanzar la verdadera vida. 


\section{BIBLIOGRAFÍA}

W.E. Besanzon, "Introduction," Herman Melville, Clarel (New York 1973).

J. L. Borges. "Nathaniel Hawthorne,". J. McIntosh, ed. Nathaniel Hawthorne's Tales (New York 1987)

L. Buonomo, Backward Glances: Exploring Italy, Reinterpreting America (1831-1866) (London 1996).

J. G. Cawelti, Adventure, Mystery and Romance: Formula Stories as Art and Popular Culture (London 1976)

W. Chatwick, Mujer, arte y sociedad. Trad. María Barberán (Barcelona 1992).

S. M. Gilbert, S. Gubar, The Madwoman in the Attic: The Woman Writer and the Nineteenth-century Literary Imagination (New Haven 1984).

N. Hawthorne, The Marble Faun (New York 1961)

---"The Old Manse." Nathaniel Hawthorne's Tales (New York 1987) 268-288.

H. Honor, Romanticism (Harmondsworth 1981).

R. W. B. Lewis, "The Return into Time: Hawthorne," A.N. Kaul, ed. Hawthorne: a Collection of Critical Essays (Prentice-Hall 1966).

F.O. Matthiessen, American Renaissance: Art and Expression in the Age of Emerson and Whitman (New York 1941).

H. Melville, "Mosses from an Old Manse." J. McIntosh, ed. Nathaniel Hawthorne's Tales (New York 1987). 337-350.

J. Porte, The Romance in America: Studies in Cooper, Poe, Hawthorne and James (Middletown, Conn. 1969).

W. Steiner, Pictures of Romance: Form against Context in Painting and Literature (London 1988) 